\title{
Positivismo e Obediência em Herbert Hart
}

\author{
Arnaldo Bastos Santos Neto ${ }^{1}$ \\ Luana Renostro Heinen ${ }^{2}$
}

\begin{abstract}
Resumo: $O$ tema do respeito à legalidade sempre serviu como ponto de acusação aos adversários do Positivismo Jurídico. O presente artigo objetiva investigar o tema da obediência às leis no pensamento do Herbert Hart, um dos juristas mais importantes do século XX, filiado à corrente denominada de Positivismo Jurídico. Veremos como Hart desenvolve uma sofisticada argumentação visando manter a separação entre direito e moral, característica diferenciadora do Positivismo Jurídico, respondendo assim às críticas de que tal corrente referendaria ordens jurídicas marcadas por situações de flagrante injustiça.
\end{abstract}

Palavras-chave: Herbert Hart. Positivismo Jurídico. Obediência às leis.

\begin{abstract}
The issue of respect for legality has always served as a point of complaint to the opponents of legal positivism. This article aims to investigate the theme of obedience to the laws in the thinking of Herbert Hart, one of the most important jurists of the twentieth century, affiliated to the current called legal positivism. We'll see how Hart developed a sophisticated argumentation in order to maintain the separation between law and morality, distinguishing characteristic of legal positivism, responding to critics that say that such current would ratify legal orders marked by situations of injustice.
\end{abstract}

Keywords: Herbert Hart. Legal Positivism. Law obedience.

\section{Introdução}

Apesar de autores como Luhmann considerarem a questão da obediência às leis como um tema que não faz sentido para uma abordagem científica do Direito, trata-se de uma temática clássica na Filosofia do Direito. A abordagem da questão remonta à peça Antígona de Sófocles, a tragédia grega em que obediência e transgressão estão em tensão com relação a nor-

1 Professor da Faculdade de Direito da Universidade Federal de Goiás e Doutor em Direito pela UNISINOS.E-mail: arnaldobsneto@yahoo.com.br.

2 Mestranda em Direito no Programa de Pós-Graduação em Direito da Universidade Federal de Santa Catarina (PPGD/UFSC), Graduada em Direito (UFG), Bolsista CNPq. E-mail: luanarh@yahoo.com.br. 
mas de direito natural e leis positivas. Perpassando todo o desenvolvimento teórico sobre o Direito, a questão da obediência à lei, como veremos, esteve presente de maneira mais forte na concepção jusnaturalista quando identificava direito natural e direito positivo (o quietismo jurídico e a obra de Cícero), mas, também, no início do desenvolvimento teórico do positivismo quando houve uma identificação entre direito e justiça ou direito e ética, o que se trata, como veremos, do positivismo ético.

Entretanto, os teóricos mais recentes do positivismo jurídico negam qualquer necessidade de obediência ao direito positivo fundada em exigências morais ou de justiça. A obra de Herbert Lionel Adolphus Hart, professor de Filosofia em Oxford, intitulada Positivism and the Separation of Law and Morals é ápice do desenvolvimento teórico do positivismo jurídico, especialmente na questão da separação entre direito e moral e sua relação com a obediência às leis. Diante de sua representatividade no contexto da teoria jurídica a obra de Hart tem, assim, justificada sua escolha neste trabalho para analisar a questão da obediência ao direito. Trata-se de um dos principais pontos de ataque dos jusnaturalistas ao positivismo, atribuindo, por exemplo, as consequências funestas dos totalitarismos da Segunda Guerra Mundial a essa concepção teórica.

\section{Obediência à Lei no Jusnaturalismo e no Positivismo: de Sófo- cles a Hebert Hart}

No dilema grego, presente na tragédia Antígona de Sófocles, o tirano Creonte insiste em aplicar as leis da pólis, mas Antígona as viola porque considera que as leis dos deuses são eternas, irrevogáveis e superiores aos códigos dos homens e, por isso, elas devem ser obedecidas. Creonte promulgou uma lei proibindo que aqueles que atentassem contra a pólis fossem sepultados e, assim, estabeleceu a morte como pena por essa desobediência. Polinice, irmão de Antígona, havia combatido na guerra civil contra seu irmão Etéocles, que apoiava Creonte. Etéocles foi sepultado, mas Polinice não. Antígona perturbou-se com a situação e seguiu o direito divino que determinava que um membro da família deveria ser sepultado por seus parentes ou seu espírito não teria descanso. Por sua desobediência às leis da 
pólis Antígona sofreu as sanções nelas previstas, mas declarava estar com sua consciência tranquila por ter agido conforme o que ordenavam as mais sagradas leis dos deuses. Para Antígona " [...] viver com o conhecimento de sua incapacidade de agir seria negar significado à sua vida e fazer dela uma não-existência (MORRISON, 2006)", enquanto Creonte considerava que o governante, a quem o Estado conferia poder, deveria ser obedecido até nas mínimas coisas, fossem justas ou injustas e justificou sua atitude com a afirmação de que a desobediência do governante era uma desgraça: "[...] ela destrói os Estados, leva os lares à ruína e, nos combates, traz consigo a derrota dos exércitos" (SOFOCLES, 1994).

A distinção conceitual entre "direito positivo" e "direito natural" está presente em toda a tradição do pensamento jurídico ocidental, sendo direito natural aquilo que é por natureza e direito positivo aquele posto ou convencionado pelos homens (BOBBIO, 1995). A defesa da existência de um direito natural contraposto ao direito positivo e localizado acima deste foi feita pelo teóricos do jusnaturalismo. Na antiguidade, Aristóteles compreendia o direito natural como universal e com um valor próprio, com bondade objetiva, enquanto o direito positivo teria eficácia apenas local e estabeleceria ações que só se tornariam obrigatórias após formuladas as leis. Para Bobbio (1995, p. 25), nesta época clássica, o direito positivo prevalecia sobre o direito natural quando houvesse um conflito e, ele também, cita como exemplo o caso de Antígona.

Na Idade Média o direito natural ligou-se a Deus. Com Santo Tomás de Aquino, por exemplo, o direito natural era compreendido como

[...] as regras que deveriam presidir a prática humana, de modo a que esta resultasse adequada aos desígnios de Deus quanto à vida em sociedade e quanto ao lugar do homem na totalidade dos seres criados (HESPANHA, 2005, p. 206).

Essas regras seriam encontradas nas escrituras ou na própria ordem do mundo. Nesse período, de acordo com Bobbio (1995, p. 25), o direito natural é considerado superior ao direito positivo.

Entre os romanos, a moral e a doutrina jurídica estóica foram difundidas pela obra de Cícero e a ela também recorreram os europeus em 
sua ânsia de retorno aos clássicos. Assim, a filosofia estóica influenciou a constituição da doutrina moderna do jusnaturalismo, com sua concepção de direito natural marcada pela generalidade, racionalidade, caráter subjetivo e tendência para a positividade. Este último ponto é especialmente importante para o presente estudo, tendo em vista que para Cícero não havia uma oposição entre direito natural e direito positivo, o que levava a um quietismo jurídico pela consumação do direito natural no direito positivo com consequente respeito deste (HESPANHA 2005, p. 294-296). Além de influenciada pela filosofia estóica, a teoria do jusnaturalismo se desenvolveu no ambiente do idealismo cartesiano e da busca por um saber racional, certo e estável. Baseou-se na crença no "poder da razão individual para descobrir as regras do justo, de um justo que fugisse à contingência, por se radicar numa ordem racional (quase matemática) da natureza (mathesis universalis) de que a razão participava", conforme Hespanha (2005, p. 295). Como representantes da doutrina do direito natural racional pode-se apontar, com algumas variações teóricas, Hugo Grotius, Thomas Hobbes, Jean-Jacques Rousseau, John Locke, Leibniz, Spinoza, Kant, Puffendorf. Assim, universalizou-se a razão humana e secularizou-se o tema. Com esses autores também desenvolveu-se a teoria do contratualismo que fundou o Estado Moderno e, ainda, tiveram grande influência nas primeiras Declarações de Direitos que consagraram os direitos naturais do homem.

Para Bobbio (1995, p. 26-29), com a criação do Estado Moderno ocorreu um processo de monopolização da produção jurídica por parte do Estado e o juiz, que antes era um livre órgão da sociedade podendo escolher entre as várias possíveis normas a aplicar (direito positivo ou normas de direito natural como princípios de razão ou equidade), tornou-se um órgão do Estado, subordinado ao legislativo, que deve aplicar normas derivadas deste ou normas reconhecidas de alguma maneira pelo Estado (consuetudinárias). $\mathrm{O}$ direito positivo aos poucos tornou-se o único e verdadeiro direito e o Estado seu único criador.

Com a Escola da Exegese, por exemplo, não se negou a existência do direito natural, mas foi desvalorizado e considerado sem importância para o jurista, enquanto não incorporado pelo direito positivo. Havia a crença de que o legislador era a autoridade adequada para estabelecer o que seria justo ou injusto, por isso, era devida obediência total ao texto da lei. 
A teoria da obediência absoluta da lei enquanto tal, bastante presente no início do desenvolvimento teórico do positivismo jurídico, é a característica do positivismo chamado por Bobbio (1995) de positivismo ético, por se tratar de uma afirmação moral ou ideológica e não científica. Para ele essa doutrina teria se desenvolvido a partir do pensamento filosófico alemão da primeira metade do século XIX, especialmente com Hegel. Segundo a concepção hegeliana o Estado teria um valor ético: “[...] é a manifestação suprema do Espírito no seu devir histórico e, portanto é ele mesmo o fim último ao qual os indivíduos estão subordinados" (BOBBIO, 1995, p .224). Essa concepção seria uma ideologia por descrever o Estado como se desejaria que ele fosse.

Ainda de acordo com Bobbio (1995, p. 227-229), haveria quatro diferentes justificações para o positivismo ético: 1) concepção cética ou realista da justiça - a justiça como expressão da vontade do mais forte, sustentada por alguns sofistas como Trasímaco no livro I da República de Platão. Conforme essa concepção, a lei é a expressão da vontade do soberano, do grupo mais poderoso e seria, assim, sempre justa; 2) concepção convencionalista da justiça - derivada do relativismo ético, considera justiça como o que os homens concordarem como tal. Ligado a essa concepção estaria Hobbes que trata de uma lei natural que impõe a observância do contrato social, compreendendo por natural uma lei que obriga em consciência. Mas, para Hobbes, haveria um limite à observância das leis caso se voltassem contra o conteúdo do contrato social, como quando o soberano colocasse em perigo a vida do súdito; 3) concepção sagrada da autoridade - o poder de mandar visto como fundado num carisma, ou seja, a figura do governante vista como sagrada, divina, que seria obedecido, portanto, não somente por medo da sanção, mas porque se consideraria um bem obedecer a suas ordens; 4) concepção do Estado ético - o Estado visto como a suprema manifestação de Deus na História é portador de uma missão, qual seja, de realizar a eticidade, que seria a manifestação de um espírito superior para o direito e para a moral. Dessa forma, as leis teriam sempre um valor ético, merecendo obediência. Essa concepção foi utilizada pela direita hegeliana.

Como se pode observar, o positivismo ético foi sustentado por poucos teóricos do positivismo e mais contemporaneamente rejeitado por completo pelos teóricos positivistas como John Austin, Hans Kelsen, Alf Ross e 
Herbert Hart, que realizaram uma separação teórica completa entre direito e moral. Sendo expressão de um momento histórico que foi o ápice da modernidade organizada, a obra de Herbert Hart é reconhecida como o apogeu do positivismo jurídico, nesse sentido Morrison (2006, p. 417). O trabalho de Hebert Hart, como veremos, procurou aplicar a análise da linguagem ordinária ou análise linguística ao campo do direito.

\section{O Positivismo Analítico de Herbert Hart}

Para Hart (2001), a tarefa principal dos juristas, antes de se dedicarem à construção de teorias, deve consistir na análise da linguagem jurídica que se usa na prática do direito. A análise lógico-semântica da linguagem e das proposições que descrevem o direito assume uma importância capital no positivismo hartiano (com influências de Ludwig Wittgenstein, Peter Winch, Friedrich Waismann e John Langshaw Austin). A busca da jurisprudência analítica diz respeito ao cuidadoso exame da linguagem ao qual o direito se formula. Como assinala Tamayo y Salmorán (2000, p. XIX), “[...] o direito será tido como um fenômeno linguístico - ser linguagem é condição de existência do direito". Hart lançou mão das conquistas filosóficas obtidas por Ludwig Wittgenstein quando da publicação deste autor da obra Investigações filosóficas, obra de sua segunda fase. Nesse livro, Wittgenstein rompe com sua teoria "fotográfica" da linguagem, tal como expõe no célebre Tractatus, e passa a dirigir sua atenção aos usos cotidianos da linguagem.

Quando falamos em linguagem, devemos ter em mente que ela expressa uma forma de vida, não podendo ser reduzida a uma série de reproduções verbais de fatos. Tais posições aparecerão na obra de Hart em sua tipologia das normas e em seu conceito de aceitação de uma norma. Assim, para Hart, as palavras utilizadas pelo direito somente podem ser entendidas dentro do discurso no qual realizam as suas funções. Desta forma, como nos explica Tamayo y Salmorán (2000, p. XXII ), "Hart no pretende, en su teoría jurídica, elaborar una definición de los términos 'norma', 'derecho', 'deber', 'contrato', etcétera; busca, simplemente, establecer las condiciones que gobiernan el uso de estas palabras”. 
A partir de uma apreciação crítica da obra de John Austin (2000), Herbert Hart (2001) propõe-se a tarefa de demonstrar a centralidade do conceito de regra para a elucidação do conceito de direito. Para Austin, não há direito sem que algumas condutas sejam tidas como obrigatórias. Uma conduta é obrigatória quando uma pessoa exige de outra que esta se submeta aos ditames da vontade daquela. Austin reduz todas as regras do sistema jurídico a ordens baseadas em ameaças coercitivas e, para ele, tais ordens devem emanar da figura de um soberano e dos seus funcionários. No capítulo III do livro $O$ conceito de direito, Hart critica a redução austiniana das regras jurídicas a regras coercitivas. Em um Estado moderno torna-se impossível reduzir todas as regras a ordens baseadas em ameaças ou em comandos, uma vez que estes possuem uma forte analogia com as leis penais. Regras que estabelecem as condições de validade de um negócio jurídico ou de um ato administrativo não são redutíveis a comandos. Hart critica ainda o fato de que no modelo de ordens coercitivas proposto por Austin, um sujeito (soberano) expressa o desejo de que outros façam ou se abstenham de fazer algo. Ocorre que, num Estado moderno, as regras não são dirigidas a pessoas singulares, mas a uma classe de destinatários. E no modelo austiniano, ocorre também outro equivoco: o soberano é excluído do âmbito de aplicação das regras por ele mesmo criado. E se as regras são criadas por um soberano, como explicar, especialmente no contexto anglo-saxônico, a criação de regras com base no costume?

Demonstradas as insuficiências do modelo precedente, Hart irá tentar explicar como as regras se coordenam para formar o que se convencionou chamar de ordenamento jurídico (legal system). Para tanto, irá decompor o modelo de regras em dois tipos: regras primárias e secundárias. As regras primárias são aquelas que estipulam um dever. Impõem um determinado comportamento a categorias de pessoas ou à totalidade dos cidadãos. Regras secundárias são aquelas que estabelecem poderes e dizem respeito à identificação, a alteração e a aplicação das regras primárias. As regras secundárias são essenciais ao ordenamento uma vez que entre as regras primárias predomina a incerteza: é necessário resolver dúvidas que surgem a todo o momento na prática judicial sobre a existência ou não de uma regra. Outro ponto, que já havia sido percebido anteriormente por Kelsen, em sua primeira versão da Teoria Pura do Direito de 1934, é que as regras primá- 
rias oferecem uma explicação estática do direito, não permitindo a compreensão de sua dinâmica. Com a criação das regras de alteração, que dizem como o direito pode criar direito, fica possibilitada a evolução do ordenamento jurídico de modo dinâmico. Uma vez que a aplicação do direito não pode ser confiada à autotutela ou a pressão difusa da comunidade, que reprova os atos que transgridem a lei, as regras secundárias estabelecem regras de julgamento, que confiam a um órgão específico a função de determinar se uma regra foi violada e providenciar a punição dos culpados.

Para a determinação da existência ou do pertencimento, ou não, de uma regra ao ordenamento entra em cena a chamada regra de reconhecimento. Com a ideia das regras de reconhecimento, Hart (2001, cap. V, p. 3) demonstra que o ordenamento não é um mero agregado amorfo de normas: “[...] as regras não são agora apenas um conjunto discreto e desconexo, mas estão, de um modo simples, unificadas". A regra de reconhecimento permite operar com a ideia de validade jurídica, uma vez que passamos a contar com uma regra que opera como regra do sistema. Deste modo, ao contrário do modelo austiniano que estabelece como fundamento de um sistema jurídico a situação social em que o soberano (uma pessoa ou grupo de pessoas) não obedece a ninguém mas conta com a obediência de todos, para Hart, o fundamento do direito consiste numa situação social em que os membros de um grupo e as autoridades possuem um critério comum de identificação das regras primárias de obrigação. A regra de reconhecimento é a regra suprema do ordenamento jurídico - substituindo assim a norma fundamental kelseniana, com a diferença que, enquanto esta é externa ao ordenamento, a regra de reconhecimento é interna ao mesmo.

A regra de reconhecimento estabelece nas sociedades modernas uma pluralidade de critérios, dispostos de forma hierárquica, culminando num critério supremo. Tal critério pode ser tido como supremo quando as regras identificadas por ele são consideradas regras do sistema, e as regras identificadas por referência a outros critérios deixam de ser consideradas regras do sistema quando em conflito com ele. A regra de reconhecimento estabelece um ponto de vista interno do direito; sendo assim, a afirmação de validade de uma regra é, também, uma afirmação interna. Regra válida é aquela identificada como regra do sistema por meio de critérios da regra de reconhecimento: "Dizer que uma regra é válida é reconhecê-la como tendo 
passado todos os testes facultados pela regra de reconhecimento e, portanto, como uma regra do sistema" (HART, 2001, cap. VI, p. 1). Mas para a regra de reconhecimento não existem critérios para fundamentação de sua própria validade, não tendo sentido falar em validade ou invalidade da regra de reconhecimento. A regra de reconhecimento existe factualmente, ou seja, é um assunto fático (a matter of fact) e deriva de uma prática social complexa. Como aponta Barzotto (2003, p. 116): "Se a regra de reconhecimento é um critério de validade, o termo "validade" não pode ser aplicado a ela, sob pena de auto-referência".

Possuindo uma existência fática, a regra de reconhecimento varia no tempo e no espaço, dependendo das práticas de indivíduos ou grupos, podendo incluir variados elementos, de natureza formal ou material. Uma regra de reconhecimento puramente formal poderia estipular que é direito aquilo que o Parlamento aprovar. Uma regra de reconhecimento de conteúdo formal e material poderia dizer: "[...] é direito aquilo que o Parlamento aprovar, desde que promova a dignidade humana e respeite os tratados internacionais de direitos humanos" (DIMOULIS, 2006, p. 119). Por conta de tal postura, Hart (2001) irá declarar que sua versão do positivismo é moderada (soft positivism).

\section{Separação entre direito e moral e a questão da obediência às leis em Herbert Hart}

Hart mantém de forma coerente o postulado positivista da separação entre o direito e a moral, argumentação que expõe no artigo Positivim and the Separation of Law and Moral (HART, 1958 p. 593-629). O que lhe valerá um ataque por parte de Lon L. Fuller (1969), que lamentará a ausência de argumentos morais na obra de Hart. A própria regra de reconhecimento de Hart também constitui uma maneira de separar o direito da moral, pois “[...] con ella es posible la determinación del perímetro completo del ordenamiento sin tener que acudir para ello a elementos ajenos al propio sistema jurídico y mantenerlo separado de la Moral'(HART, 2001, p. 223-224), assim, as normas não são válidas conforme seu conteúdo, mas porque são criadas ou reconhecidas de fato pela sociedade de uma maneira contingen- 
te. Defendendo Austin e Kelsen das acusações habituais contra positivistas (de abrirem caminho para um direito imoral), Hart escreveu uma passagem famosa pela fórmula com que sintetiza sua posição:

O que estes pensadores estavam essencialmente preocupados em promover era a clareza e a honestidade na formulação das questões teóricas e morais suscitadas pela existência de leis concretas que eram moralmente iníquas, mas foram legisladas de forma devida, claras no seu sentido, e satisfizeram todos os critérios reconhecidos de validade de um sistema. A sua visão foi a de que, ao pensar em tais leis, quer o jurista teórico, quer os infelizes funcionários ou o cidadão privado que foram chamados a aplicá-las ou a obedecer-lhes, só podiam ser confundidos por um convite de recusa do título de "direito" ou de "validade" relativamente a elas. Pensaram que, para encarar tais problemas, existiam recursos mais simples e cândidos, que iluminariam muito melhor todas as considerações intelectuais e morais relevantes: devíamos dizer: "isto é direito; mas é demasiado iníquo para poder ser aplicado ou obedecido" (HART, 2001, p. 223-224, grifo nosso).

Comentando a fórmula hartiana "[...] isto é direito; mas é demasiado iníquo para poder ser aplicado ou obedecido.”, Saavedra López (2006, p. 255) escreveu que com "[...] estas palabras el positivismo jurídico parece quedar reconciliado com las pretensiones éticas del humanismo" ante as atrocidades cometidas com os instrumentos do direito, especialmente nos países que viveram experiências totalitárias. Sendo assim,

El derecho injusto no es derecho nulo. Pero que el derecho exista y sea válido no implica que se le deba obediencia, moralmente hablando. El derecho obliga, jurídicamente hablando, porque cumple los requisitos establecidos en la norma a la que debe su existencia, y en último término, obliga porque cumple os requisitos establecidos en la norma de reconocimiento, una norma soberana sobre cuya razón de validez es absurdo preguntar porque, desde un punto de vista teórico o intelectual, no hay más remedio que verla como un hecho incontestable. Y, por otro lado, el derecho obliga, moralmente hablando, si cumple las exigencias morales que la persona moral, la persona que pone en juego su capacidad de enjuiciamiento mo- 
ral, estima suficientes para destinarle obediencia. Al César lo que es de del César, y a Dios lo que es de Dios (LÓPEZ, 2006, p. 256).

Ao assumir os postulados teóricos da filosofia da linguagem ordinária ou natural, Hart inicia a recuperação da racionalidade do discurso ético. Por meio dessa abordagem, Hart poderá verificar o contexto em que determinadas frases ou expressões são utilizadas no uso comum da linguagem. Num dos capítulos de sua obra, $O$ conceito de direito, dedicado ao tema da justiça cujo título é Justiça e Moral, Hart (2001, p. 171) lembra que os termos mais usados pelos juristas para elogiar ou condenar o direito ou a sua aplicação são as palavras 'justo' ou 'injusto'. Por exemplo: seria estranho ouvir que um homem que espanca seu filho agiu de forma 'injusta'. Geralmente dizemos que tal homem, agindo contra seu filho, fez um 'mal', algo moralmente 'ruim' ou 'perverso'. Por outro lado, caso tal homem tivesse escolhido arbitrariamente um dos seus filhos para uma punição mais severa que a punição infligida aos outros, culpados igualmente por uma falta qualquer, a palavra 'injusto’ seria apropriada. Para Hart, dizer que uma lei é administrada de forma justa é dizer que ela é imparcialmente aplicada para todos aqueles e somente para aqueles que são similares nos aspectos relevantes apontados pela própria lei. Assim, paradoxalmente, é possível que uma lei injusta seja aplicada justamente. Hart entende que há um princípio latente nas diversas aplicações da ideia de justiça, o de que os indivíduos têm direito, em suas relações recíprocas, a certa posição relativa de igualdade ou desigualdade.

Desse modo, Hart também parte da distinção entre a justiça na aplicação das normas e a justiça das normas, mas considera que se pode estabelecer racionalmente os conteúdos mínimos da justiça. Ou, como sublinha Atienza (1994, p. 157): “[...] es decir, que se pueden justificar racionalmente ciertas reglas de conducta que toda organización social debe contener para ser viable y que él denomina 'contenido mínimo de Derecho Natural"'. Tais normas de direito natural derivariam de uma série de características das sociedades humanas, tais como a vulnerabilidade (o que leva à proibição do homicídio), a igualdade aproximada entre os homens (o que obriga passar das formas morais às formas jurídicas, uma vez que ninguém pode dominar sem concessões e abstenções), o altruísmo limitado, pois os 
homens não são anjos nem demônios (que também leva à criação de regras que prescrevam abstenções), a limitação dos recursos (que obriga a adoção de formas mínimas de propriedade, seja pública ou privada) e, finalmente, compreensão e força de vontade limitada, o que também leva à adoção do direito. Todavia, a concepção de Hart, fortemente inspirada em Hobbes, diferencia-se do jusnaturalismo. O conteúdo mínimo de direito natural que ele postula não possui caráter imutável e Hart reconhece que as vantagens de tais regras nem sempre foram estendidas a todas as pessoas. No comentário de Atienza:

Así pues, faltarían las notas de inmutabilidad de universalidad que utilizamos en su momento para caracterizar la concepción iusnaturalista de la justicia. El segundo, que afecta más a la teoría del Derecho que a la de la justicia, se refiere a la distinta manera de entender las relaciones entre el Derecho y la moral. Al igual que los iusnaturalistas, Hart acepta que existe una importante conexión entre el Derecho y la moral tanto a nivel lingüístico y conceptual, como desde el punto de vista del contenido: su teoría del contenido mínimo de Derecho natural permite explicar la existencia de una zona más o menos amplia de confluencia entre el Derecho y la moral. Pero, a diferencia de los iusnaturalistas, Hart mantiene netamente la distinción entre la validez y la justicia del Derecho (entre el Derecho y la obligación de obedecer al Derecho). Así, una norma tiene carácter jurídico - pertenece a un determinado sistema jurídico - no por razones morales, sino porque el propio ordenamiento jurídico o, si se prefiere, su regla de reconocimiento, le otorga validez jurídica (ATIENZA, 1994, p. 158).

Segundo Hart, o ponto de vista jusnaturalista, oposto ao positivista, que atribui invalidade às normas moralmente iníquas, parece atraente quando se trata de castigar iniquidades cometidas em forma juridicamente autorizada por particulares ou mesmo funcionários públicos durante um regime anterior, marcado pelo totalitarismo ou uma "revolução". Ora como castigar atos perversos que eram autorizados ou exigidos pelo direito do regime anterior? O castigo pode ser visto como socialmente desejável, entretanto, recorrer a uma legislação francamente retroativa também soa moralmente odioso. Então, aparenta ser tentador afirmar que "[...] as leis que se asso- 
ciaram à iniquidade ou a permitiram não deviam ser reconhecidas como válidas, ou não deviam ter a qualificação de direito"(HART, 2001, p. 224). Argumentos de Direito Natural foram, dessa forma, suscitados, por exemplo, na Alemanha pós-nazismo. Para Hart o que está em jogo entre aqueles que apoiam a invalidade das normas de direito iníquas e os positivistas é, na verdade, o mérito comparado de um conceito ou um modo de classificar regras mais amplo e um mais restrito. O conceito de direito mais amplo inclui seu rival mais restrito. A escolha racional entre eles, para Hart, implica reconhecer que um é superior ao outro e auxiliar as pesquisas teóricas e/ou clarificar as deliberações morais.

O conceito mais amplo de direito, considera direito inclusive as regras que violem a moral de uma sociedade ou aquilo que se considere uma moral esclarecida. Já o conceito mais restrito de direito exclui dessa classificação tais regras moralmente ofensivas. Considera Hart que o conceito mais amplo possibilita uma abrangência maior dos estudos jurídicos, estendendo as possibilidades de compreensão dos métodos de controle social num sistema de regras primárias e secundárias. Contrariamente, o conceito mais restrito prejudicaria a compreensão do fenômeno.

Além disso, Hart alerta para o fato de que educar os homens para um conceito mais restrito de validade jurídica, que excluísse as leis perversas como inválidas, dificilmente conduziria a uma "[...] resistência ao mal, perante ameaças do poder organizado, ou a um entendimento mais perfeito do que está moralmente em jogo, quando se pede obediência" (HART, 2001, p. 227). O direito continuaria, ainda assim, sendo um possível instrumento de dominação em mãos de homens perversos:

Enquanto os seres humanos puderem conseguir a suficiente cooperação de alguns, de forma a permitir-lhes dominar os outros, utilizarão as formas do direito como um dos seus instrumentos (HART, 2001, 227).

Então, lembra Hart que diante de uma situação de abuso de poder, o que é de fato necessário é que os homens

[...] preservem o sentido de que a certificação de algo como juridicamente válido não é concludente quanto à questão da obediência e 
que, por maior que seja a aura de majestade ou de autoridade que o sistema oficial possa ter, as suas exigências devem no fim ser sujeitas a exame moral (HART, 2001, p. 227).

Hart (2001, p. 228) assinala também que negar validade a leis iníquas é um simplismo exagerado e grosseiro: “[...] uma atitude demasiado brutal para com complexas e delicadas questões morais". Isso porque além da questão moral de se obedecer ou não a uma regra má, há também a questão da submissão: deveria sujeitar-me ao castigo devido pela desobediência ou deveria fugir? E, ainda, há a questão posta pelos tribunais alemães do pós-guerra de se deveriam punir aqueles que fizeram coisas más quando eram permitidas por regras também más, em vigor naquele momento. Essas questões são, para Hart, problemas muito diferentes, de moral e justiça, que não podem ser simplificada e definitivamente resolvidos com a negativa de vigência às leis iníquas. Assim, a posição positivista trata de lançar luz às questões, tendo em vista que a distinção entre invalidade e imoralidade do direito permite ver a complexidade e a variedade dessas questões de maneira separada, enquanto que um conceito restrito de direito nos cega para elas: “[...] que as regras moralmente iníquas podem ser ainda direito [...] não mascara a escolha entre males que, em circunstâncias extremas, pode ter de ser feita" (HART, 2001, p. 228).

Hart chega a afirmar que há duas condições mínimas necessárias e suficientes à existência de um sistema jurídico - que seria, por isso, bifronte: as regras primárias (de comportamento, conformes à regra de reconhecimento) devem ser em geral obedecidas pelos cidadãos e, por outro lado, as regras de reconhecimento que especificam os critérios de validade jurídica e as regras de alteração e julgamento (regras secundárias) devem ser efetivamente aceitas pelos funcionários do sistema como "padrões públicos e comuns de comportamento oficial" (HART, 2001, p. 228). Assim, os funcionários devem "[...] encarar estas regras como padrões comuns de comportamento oficial e considerar criticamente como lapsos os seus próprios desvios e os de cada um dos outros", defende Hart (2001, p. 128). Essa dualidade é característica dos sistemas jurídicos compostos por regras primárias e secundárias, diferentemente dos sistemas pré-jurídicos mais simples em que só havia regras primárias, aceitas como padrões de comportamento. 
Cabe às autoridades uma concepção mais complexa, não somente uma mera obediência. Pois a obediência, segundo Hart, pode se dar por qualquer motivação e não exige, necessariamente, qualquer reflexão quanto ao comportamento de acatamento ser correto ou obrigatório. Nos dizeres de Morrison:

[...] cabe às autoridades ostentar essa atitude especial, que parece equivaler a um compromisso consciente e explícito com a observação das regras enquanto característica central da atitude oficial de tais autoridades em sua condição de 'juízes', etc. (MORRISON, 2006, p. 443).

Essa atitude especial das autoridades implica também que quando se desviem das regras devem preocupar-se com tais desvios como lapsos em relação aos padrões públicos comuns. Não se trata de mera questão de eficiência ou sanidade do sistema, mas é uma condição logicamente necessária para falar da existência do sistema, de forma a manter sua unidade e continuidade.

Já aos cidadãos comuns cabe obedecer em termos gerais às regras do sistema. Obediência que pode se dar por uma variedade de razões:

[...] a sua lealdade ao sistema pode ser baseada em considerações muito diferentes: cálculos acerca de interesse a longo prazo; preocupação desinteressada quanto aos outros; atitude não crítica, herdada ou tradicional; ou o mero desejo de fazer como os outros fazem (HART, 2001, p. 219).

Essa obediência geral é uma prova e uma condição necessária da existência do sistema jurídico: “[...] a cooperação voluntária de um número suficiente de indivíduos cria autoridade e permite que se estabeleça o poder coercitivo do direito e do governo", de acordo com Hart (2001, p. 217).

Assim, se não houvesse uma obediência geral das regras do sistema de maneira completa e prolongada, caso seja um novo sistema, para Hart (2001, p. 115) nunca teria se estabelecido como sistema jurídico; já no caso de um sistema já estabelecido, teria deixado de ser o sistema jurídi- 
co de determinado grupo. Nesse ponto, Hart se aproxima de Kelsen (1998, p. 236) quando este afirma que a ineficácia geral do sistema jurídico produz sua derrogação: “[...] não pode negar-se que uma ordem jurídica como um todo, tal como uma norma jurídica singular, perde a sua validade quando deixa de ser eficaz [...]". Entretanto, a necessidade de um mínimo de obediência para que o sistema jurídico exista e seja duradouro não implica numa obrigação moral de obedecer ao direito como condição lógica e necessária de sua existência:

Por supuesto que es probablemente verdadero que, a menos que una mayoría coopere voluntariamente a obedecer las reglas de un sistema jurídico coactivo, éste no podrá perdurar. Inclusive puede ser verdadero que a menos que un grande número de esos individuos crea que tanto ellos mismos como los demás están moralmente obligados a obedecer ese orden, el sistema podría ser muy inestable. Pero esto es insuficiente para demostrar la pretendida conexión lógica entre 'existe un sistema jurídico en Inglaterra' y 'en Inglaterra existe un reconocimiento general de una obligación moral de obedecer al derecho', aun cuando el primero de estos enunciados sea ciertamente verdadero y el segundo probablemente lo sea (HART, 1977, p. 16).

A prática social complexa é suficiente para responder de modo afirmativo a pergunta de se um sistema jurídico existe, de acorco com Hart (1977, p. 17). Como já foi dito, Hart nega a existência de um juízo moral de que é certo fazer o que o direito exige. Isso porque as motivações de obediência ao direito podem ser as mais variadas possíveis. Além disso, aqueles que aceitam a autoridade do sistema podem examinar sua consciência e decidir que, moralmente, não deviam aceitá-la, mas continuam fazendo por outros motivos. Podem, ainda, reconhecer, conforme sua consciência, a imoralidade de certas regras do sistema e, por tal motivo, desobedecê-las. Nesse caso, caber-lhes-á resolver as outras questões, já referidas, decorrentes dessa desobediência. 


\section{Considerações Finais}

A obra de Hebert Hart, ápice do positivismo jurídico, com sua proposta de análise da linguagem dentro do discurso em que é utilizada, possibilita de maneira sofisticada refutar as críticas feitas ao positivismo jurídico de que exigiria a obediência ao direito, mesmo quando este consagrasse leis iníquas. Essas acusações não procedem, ainda mais quando dirigidas contra o positivismo jurídico do século XX.

O critério de validade das leis positivas, para os positivistas, não é moral, realizam uma separação entre direito e moral, mas não negam suas conexões e, especialmente Hart, afirma a necessidade da existência de um conteúdo mínimo de direito natural. Trata-se de um conteúdo mínimo que toda organização baseada no direito deveria ter para que pudesse ser viável.

Da mesma maneira, para que um sistema jurídico se estabeleça e seja durável, Hart propugna que deve ser obedecido em geral pelos seus cidadãos e que as autoridades desse sistema devem considerar suas regras como padrões de públicos de comportamento, sendo sua possível violação um lapso a ser adequadamente observado. Esses requisitos não dizem respeito à mera eficiência ou sanidade do sistema, mas se referem a sua própria existência com unidade e continuidade.

Entretanto, essa obediência não implica num reconhecimento moral de que o sistema deve ser obedecido. Apesar de admitir que isso possa acontecer, ou seja, que possa haver um juízo moral de necessidade de obediência ao sistema jurídico e de que isso possa auxiliar sua perpetuidade, Hart nega sua conexão lógica com a existência do próprio sistema. Ora, a obediência às leis pode se dar pelos mais variados motivos, egoístas, inclusive, e não necessariamente por critérios morais. Além disso, as leis positivas estão sujeitas a análise moral crítica pelos indivíduos, que podem se recusar a obedecê-las devido sua imoralidade. Então, caberá ao indivíduo resolver as outras questões de justiça e moralidade decorrentes disso: sofrer a sanção ou fugir, tendo em vista que a sanção pode não the parecer justa. Por fim, o positivismo jurídico lança luz a questões que são morais, ao invés de simplificadamente negar validade a leis iníquas e mascarar essas questões. 


\section{Referências}

ALEIX, Cristina Fuertes-Planas. Validez, obligatoriedad y eficacia del derecho en H. L. A. Hart. In: Anuario de Derechos Humanos, Nueva Época, v. 8, 2007.

ATIENZA, Manuel. Introducción al Derecho. Barcelona: Barcanova, 1994.

AUSTIN, John. The province of jurisprudence determined. Nova York: Prometheus, 2000.

BARZOTTO, Luís Fernando. O positivismo jurídico contemporâneo. Uma introdução a Kelsen, Ross e Hart. São Leopoldo: Unisinos, 2003.

BOBBIO, Norberto. Positivismo Jurídico: Lições de Filosofia do Direito. Tradução: Márcio Pugliesi. São Paulo: Ícone, 1995.

DIMOULIS, Dimitri. Positivismo Jurídico. Introdução a uma teoria do direito e defesa do pragmatismo jurídico-político. São Paulo: Método, 2006.

FULLER, Lon L. The morality of law. Yale University Press, 1969.

HART. H. L. A. Positivism and the Separation of Law and Morals. In: Harvard Law Review, v. 71, número 4, fevereiro de 1958, p. 593-629.

. Obligación jurídica y obligación moral. Cuadernos de crítica 3. México: Universidad Nacional Autónoma de México, 1977.

. O conceito de direito. 3. ed. Tradução de A. Ribeiro Mendes.

Lisboa: Calouste Gulbenkian, 2001.

HESPANHA, António Manuel. Cultura Jurídica Européia: síntese de um milênio. Florianópolis: Fundação Boiteux, 2005.

KELSEN, Hans. Teoria Pura do Direito. Tradução: João Baptista Machado. São Paulo: Martins Fontes, 1998. 
LÓPEZ, Modesto Saavedra. Las opiniones de H. L. A. Hart sobre el derecho injusto. In: RAMOS PASCUA, J. A.; RODILLA GONZÁLEZ, M. A. (Orgs.). El positivismo jurídico a examen. Estúdios em homenaje a José Delgado Pinto. Salamanca: Ediciones Universidad de Salamanca, 2006.

MORRISON, Wayne. Filosofia do direito: dos gregos ao pósmodernismo. Tradução: Jefferson Luiz Camargo. São Paulo: Martins Fontes, 2006.

SOFOCLES. A trilogia tebana; Edipo rei, Edipo em Colono, Antígona. 4. ed. Rio de Janeiro: J. Zahar, 1994.

TAMAYO y SALMORÁN, Rolando. Hart y la teoría jurídica analítica. In: HART, H. L. A., Post Scriptum al concepto de derecho. Introdução e tradução de Rolando Tamayo y Salmorán. México: UNAM, 2000.

Recebido em: 12/09/2010

Revisado em: $30 / 09 / 2010$

Aprovado em: 23/10/2010 